\title{
From Ruthenium to Copper: A la carte Tools for the Synthesis of Molecules of Interest
}

\author{
Florian Monnier* and Marc Taillefer
}

\begin{abstract}
Well-defined ruthenium complexes and simple copper-ligand systems proved to be powerful catalysts for the construction of complex molecules from simple and abundant organic sources. In this account, chosen examples of reactions involving $\mathrm{C}-\mathrm{C}$ bond formation catalyzed by $\left[\mathrm{Ru}\left(\eta^{5}-\mathrm{C}_{5} \mathrm{H}_{5}\right)-\left(\mathrm{CH}_{3} \mathrm{CN}\right)_{3}\right]\left[\mathrm{PF}_{6}\right]$ will be presented. A practical synthesis of the versatile catalyst $\left[\mathrm{Ru}\left(\eta^{5}-\mathrm{C}_{5} \mathrm{H}_{5}\right)-\left(\mathrm{CH}_{3} \mathrm{CN}\right)_{3}\right]\left[\mathrm{PF}_{6}\right]$ is also described via a simple and easy-handled procedure discovered in Geneva ten years ago. The second part of this review is focused on methodologies catalyzed by an association of a copper salt and a simple ligand for the formation of $\mathrm{C}-\mathrm{N}, \mathrm{C}-\mathrm{O}$ and $\mathrm{C}-\mathrm{C}$ bonds developed in our group in Montpellier. A brief overview of applications in life sciences and materials will conclude this article.
\end{abstract}

Keywords: Catalysis · Copper · Cross-coupling $\cdot$ Ruthenium

\section{Ruthenium Catalysts: The Power of Coupling}

\subsection{Synthesis of Ruthenium Catalysts}

Developing methods to produce highly interesting ruthenium catalysts is greatly desirable to provide and simplify the access route to well-defined catalysts for non-specialist chemists. Thus, during my stay in Geneva, Peter Kündig and I decided to focus on a very simple strategy to synthetize $\left[\mathrm{Ru}\left(\eta^{5}-\mathrm{C}_{5} \mathrm{H}_{5}\right)-\left(\mathrm{CH}_{3} \mathrm{CN}\right)_{3}\right]\left[\mathrm{PF}_{6}\right]$ catalyst (also referred to as [ $\left.\mathrm{CpRu}\left(\mathrm{CH}_{3} \mathrm{CN}\right)_{3}\right]$ $\left.\left[\mathrm{PF}_{6}\right]\right)$. The latter was widely used by many organic groups around the world, especially in Trost's group in Stanford for key steps in the synthesis of complex natural products (Fig. 1). This catalyst is one of the most widely used ruthenium complexes in fine chemistry ${ }^{[1]}$ after the well-know metathesis catalysts developed by Grubbs and Hoveyda. ${ }^{[2]}$ Institut Charles Gerhardt, CNRS UMR 5253, AM2N 8 rue de l'Ecole Normale

34296 Montpellier Cedex 05, France.

E-mail: florian.monnier@enscm.fr
Due to the facile lability of the acetonitrile ligands, $\left[\mathrm{CpRu}\left(\mathrm{CH}_{3} \mathrm{CN}\right)_{3}\right]\left[\mathrm{PF}_{6}\right]$ presented diversified reactivity and applications. As shown in Fig. 1, this complex, acting as a (pre)catalyst, has demonstrated a high potential for the construction of $\mathrm{C}-\mathrm{C}$ bonds in natural product total synthesis. Furthermore the $[\mathrm{CpRu}]^{+}$fragment could be associated with arene to form the $[\mathrm{CpRu}(\text { arene })]^{+}$complex. The latter easily undergoes nucleophilic addition and substitution reactions on the arene. ${ }^{[3]}$ The $[\mathrm{CpRu}]^{+}$fragment has also shown activity in Ru-labeling of biological compounds. ${ }^{[4]}$ It is noteworthy that the association of the [CpRu] fragment with chiral ligands could also undergo asymmetric reactions such as the Diels-Alder reaction ${ }^{[5]}$ or dehydrative C-, N- or O-allylation ${ }^{[6]}$ respectively with a BINOL-type ligand and bidendate $\mathrm{sp}^{2} \mathrm{~N}$ ligand.

The $\left[\mathrm{Ru}\left(\eta^{5}-\mathrm{C}_{5} \mathrm{H}_{5}\right)-\left(\mathrm{CH}_{3} \mathrm{CN}\right)_{3}\right]\left[\mathrm{PF}_{6}\right]$ catalyst was first synthetized and described by Gill and Mann in 1982.[7] They used a three-step route based on the substitution of chloride in $\left[\left(\mathrm{Ru}\left(\mathrm{C}_{6} \mathrm{H}_{6}\right) \mathrm{Cl}_{2}\right]_{2}\right.$ by cyclopentadienide using TlCp followed by photolytic Ru-arene bond cleavage. The use of highly toxic thallium salts and a photochemical final step was not so useful, especially for non-organometallic specialists (Scheme 1).

Twenty years later, Trost and Older proposed an alternative to the previous

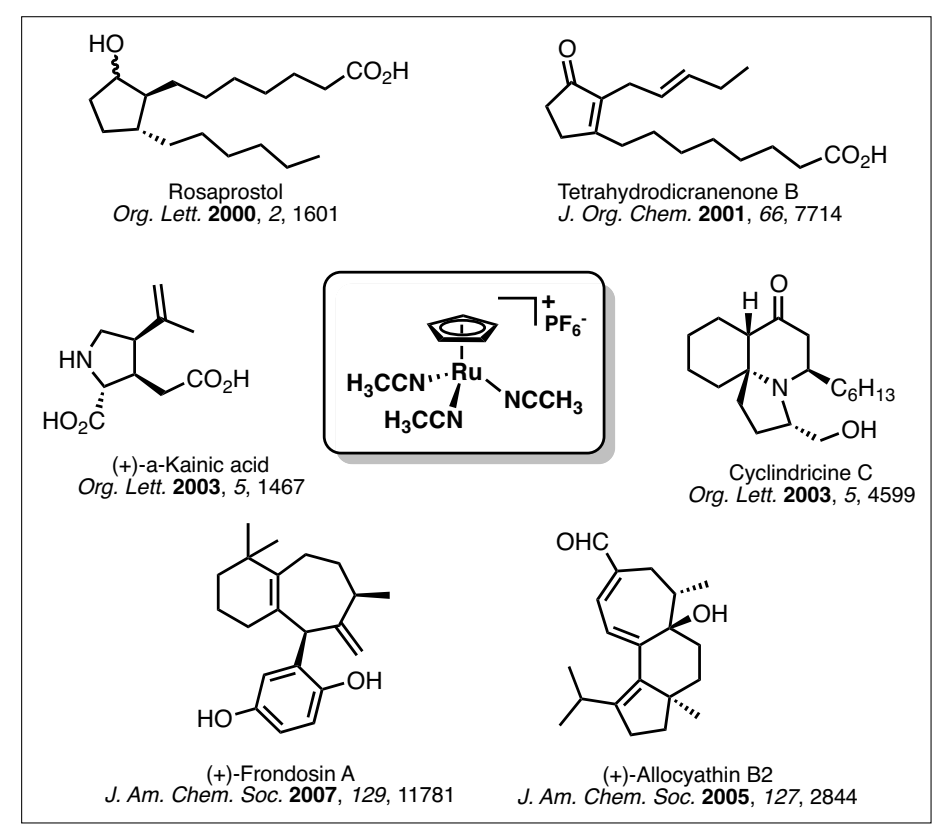

Fig. 1. Natural products synthesized in the group of $B$. M. Trost using $\left[\mathrm{Ru}\left(\eta^{5}\right.\right.$ $\left.\left.\mathrm{C}_{5} \mathrm{H}_{5}\right)-\left(\mathrm{CH}_{3} \mathrm{CN}\right)_{3}\right]\left[\mathrm{PF}_{6}\right]$ as a catalyst in one of the steps. 
synthesis by replacing thallium salts by $\mathrm{K}_{2} \mathrm{CO}_{3}$ to displace an arene moiety. ${ }^{[8]}$ On the other hand, a photochemical step was still necessary to complete the synthesis (Scheme 1).

Then at the end of 2003, we started to think about a very simple and easy procedure to synthetize this 'magic' catalyst. The idea was to avoid the use of thallium chemistry completely, and also to remove the inconvenient photochemical final step. After 4-5 months of intense literature and experimental studies, we found the 'voie royale' for the large-scale synthesis of this powerful catalyst: from easily prepared ruthenocene, one $\mathrm{Cp}$ ring was displaced by a naphthalene ring with $\mathrm{TiCl}_{4}$ to form dichloride titanocene and a cationic ruthenium complex with one naphthalene ring and one $\mathrm{Cp}$ ring. Then the labile naphthalene was removed by acetonitrile to the desired complex in very good yields without any photochemical activation by UV. ${ }^{[9]}$ It is noteworthy that this high valuable catalyst has been synthetized in large scale $(7 \mathrm{~g}$ ) without loss of yield (Scheme 2).

Nowadays, this simple route to the catalyst is used by synthetic chemists, especially by J. Lacour's group who developed very nice and novel methodologies for the formation of $\mathrm{C}-\mathrm{C}$ bonds or $\mathrm{O}-\mathrm{H}$ and $\mathrm{C}-\mathrm{H}$ insertion reactions ${ }^{[10]}$ and also 1,4-dioxene synthesis from epoxides and diazo compounds. ${ }^{[10 \mathrm{~d}]}$

\subsection{Synthetic Applications of Cata- lyst $\left[\mathrm{Ru}\left(\eta^{5}-\mathrm{C}_{5} \mathrm{H}_{5}\right)-\left(\mathrm{CH}_{3} \mathrm{CN}\right)_{3}\right]\left[\mathrm{PF}_{6}\right]$}

As mentioned above, the catalyst $\left[\mathrm{Ru}\left(\eta^{5}-\mathrm{C}_{5} \mathrm{H}_{5}\right)-\left(\mathrm{CH}_{3} \mathrm{CN}\right)_{3}\right]\left[\mathrm{PF}_{6}\right]$ is widely used by many organic research groups around the world to develop the construction of complex molecules. ${ }^{[1]}$

Among them, the group of B. M. Trost developed a myriad of methodologies for the formation of $\mathrm{C}-\mathrm{C}$ bonds starting from simple unsaturated molecules. Some chosen examples are discussed in the following account.

\subsubsection{Coupling of Alkyne and Alkene: Access to Natural Products}

In the first decade of the new millennium, Trost et al. largely developed methodologies for the coupling of various alkynes and alkenes catalyzed by $\left[\mathrm{Ru}\left(\eta^{5}\right.\right.$ $\left.\left.\mathrm{C}_{5} \mathrm{H}_{5}\right)-\left(\mathrm{CH}_{3} \mathrm{CN}\right)_{3}\right]\left[\mathrm{PF}_{6}\right]$, most commonly $[\mathrm{CpRu}(\mathrm{II})]^{+}$catalysts. This reaction consists of the formation of a novel $\mathrm{C}-\mathrm{C}$ bond via the coupling of an alkyne with an alkene, and could afford two regioisomeric products: a branched and a linear 1,4-diene (Scheme 3).

From a mechanistic view, the initial oxidative coupling of the two unsaturated partners constitutes the key step of this reaction and gives a ruthenacyclopentene intermediate. Then $\beta$-hydride elimination

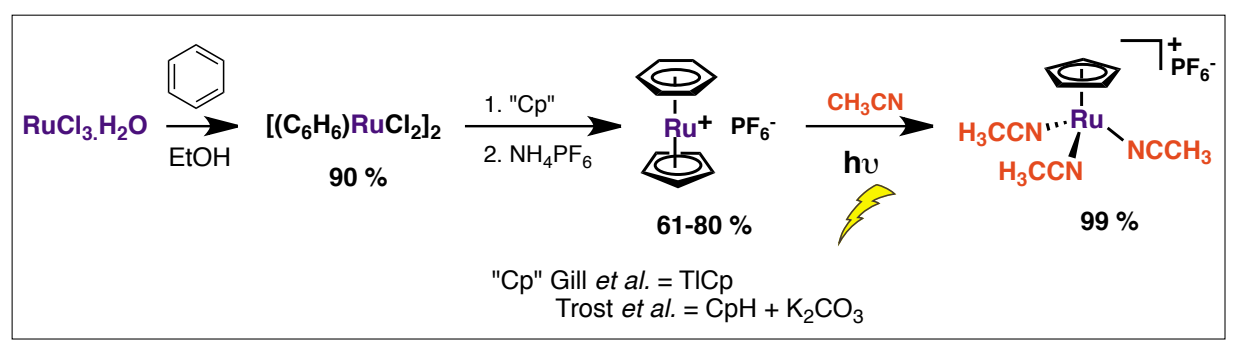

Scheme 1. Photochemical accesses to $\left[\mathrm{Ru}\left(\eta^{5}-\mathrm{C}_{5} \mathrm{H}_{5}\right)-\left(\mathrm{CH}_{3} \mathrm{CN}\right)_{3}\right]\left[\mathrm{PF} \mathrm{F}_{6}\right]$ by Gill and Trost.

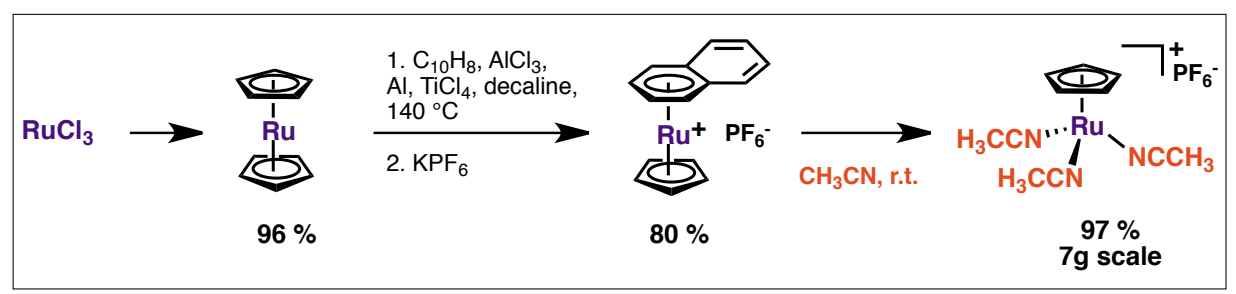

Scheme 2. The 'voie royale' for the synthesis of $\left[\mathrm{Ru}\left(\eta^{5}-\mathrm{C}_{5} \mathrm{H}_{5}\right)-\left(\mathrm{CH}_{3} \mathrm{CN}\right)_{3}\right]\left[\mathrm{PF}_{6}\right]$.

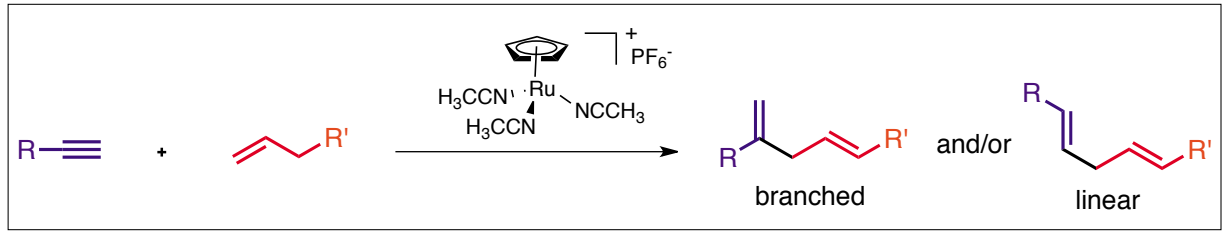

Scheme 3. $\left[\mathrm{CpRu}\left(\mathrm{CH}_{3} \mathrm{CN}\right)_{3}\right]\left[\mathrm{PF}_{6}\right]$ catalyzed 1,4-diene formation.

affords two regioisomeric vinyl ruthenium intermediates. The latter could release a 1,4-diene after reductive elimination (Scheme 4, $\mathrm{S}=\mathrm{CH}_{3} \mathrm{CN}$ ).

This powerful methodology was illustrated by the total synthesis of two natural products. Callipeltoside $\mathrm{A}$ is a natural product from a marine lithistida sponge (Callipelta sp.) with excellent prospects for treatment of cancer. ${ }^{[11]}$ A key step in the synthesis of this complex molecule by Trost's group consisted of the Ru-cata-

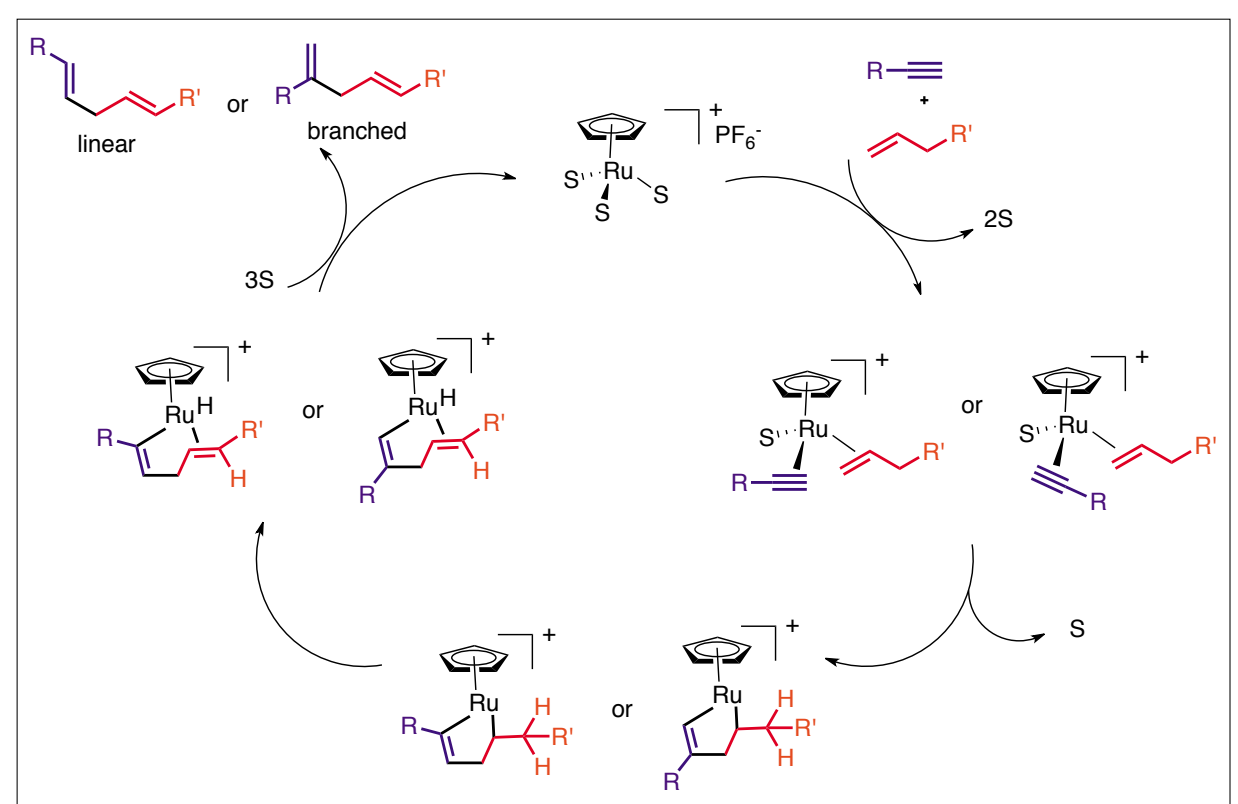

Scheme 4. Postulated mechanism for the [CpRu]-catalyzed coupling of alkyne and alkene. lyzed coupling of a terminal alkene with a disubstituted alkyne. The coupling product was obtained in $85 \%$ yield and constitutes the backbone of callipeltoside A (Scheme 5). ${ }^{[12]}$

The second significant example of application of this alkyne-alkene coupling is the formal synthesis of (-)-mycalamide A. This molecule is produced by a natural marine sponge, and presented interesting antiviral and antitumoral properties. ${ }^{[13]}$ The left part of this molecule was built 


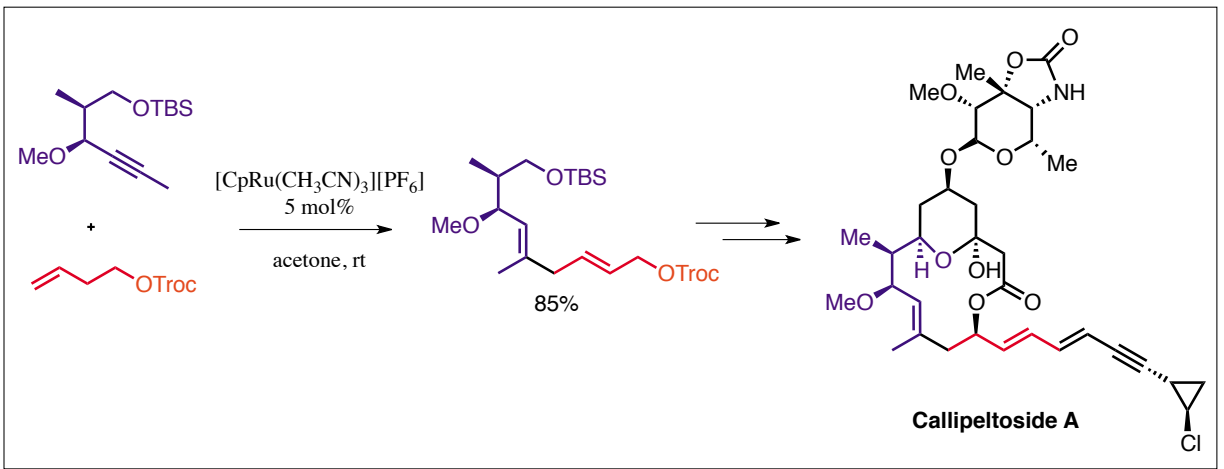

Scheme 5. [CpRu]-catalyzed preparation of the 1,4-diene for the total synthesis of callipeltoside A.

in several steps; the first one required the [CpRu]-catalyzed coupling of an alkyne and an alkene. The corresponding branched 1,4-diene was selectively obtained in $63 \%$ yield (Scheme 6). ${ }^{[14]}$

\subsection{2 [CpRu]-catalyzed Alkyne-Alkyne Coupling Reactions}

As shown in Scheme 4, the key intermediate of the alkene-alkyne coupling catalyzed by $[\mathrm{CpRu}]$ is believed to be a ruthenacyclopentene complex. In the case of alkyne-alkyne coupling, a ruthenacyclopentadiene is postulated in many reactions with this catalyst.

Based on this type of mechanism, dimerization of propargylic alcohols in the presence of water was described in 2001.[15] This reaction afforded $\alpha, \beta, \gamma, \delta$ unsaturated ketones in excellent yields with good selectivity. The postulated mechanism is the following: the [CpRu] coordinates two molecules of propargylic alcohol by oxidative coupling to afford the ruthenacyclopentadiene A. Then a carbene intermediate $\mathrm{B}$ is formed by elimination of a molecule of water. This free molecule of water adds to the carbene carbon atom to afford intermediate $\mathrm{C}$, which can evolve by $\beta$-hydride elimination and reductive elimination to release the corresponding $\alpha, \beta, \gamma, \delta$-unsaturated ketone (Scheme $7, \mathrm{R}$ $=$ alk, $\mathrm{S}=\mathrm{CH}_{3} \mathrm{CN}$ ).

This methodology has been demonstrated and adapted in an intramolecular way for the total synthesis of (+)- $\alpha$-kainic acid. Starting from a protected aminodiyne, the [CpRu] catalyst is able to perform a cycloisomerization reaction ${ }^{[16]}$ to afford a Nheterocycle in $80 \%$ yield. The latter constitutes the backbone for the total synthesis of (+)- $\alpha$-kainic acid after four synthetic steps (Scheme 8). [17]

The power of $\left.\left[\mathrm{CpRuCH}_{3} \mathrm{CN}\right)_{3}\right]\left[\mathrm{PF}_{6}\right]$ for the formation of $\mathrm{C}-\mathrm{C}$ and $\mathrm{C}$-heteroatom bonds has also been demonstrated by the total synthesis of (-)-lasonolide $\mathrm{A},{ }^{[18]}(-)$-pseudolaric acid $\mathrm{B},{ }^{[19]}$ bryostatin analogue, ${ }^{[20]}$ amphidinolide $\mathrm{P},{ }^{[21]}(+)$-allocyathin $\mathrm{B} 2,{ }^{[22]}(+)$-cylindricine $\mathrm{C}, \mathrm{D}$, and $\mathrm{E},{ }^{[23]}(-)$-exiguolide. ${ }^{[24]}$

\section{A la carte Catalyst: The Copper Toolbox}

In 2006, I joined the group of Marc Taillefer as assistant professor in Ecole Nationale Supérieure de Chimie de Montpellier. His discoveries with respect to Ullmann reactions had been patented a few years previously, ${ }^{[25]}$ and I was impressed

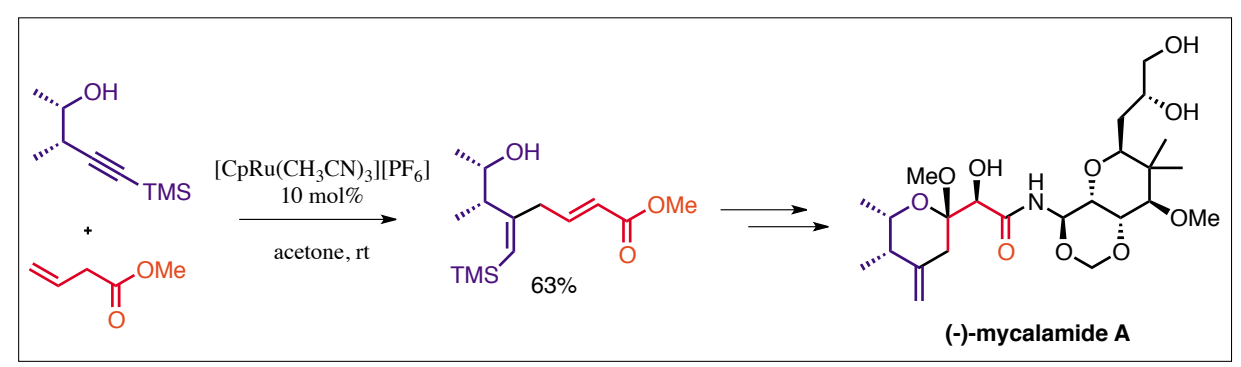

Scheme 6. [CpRu]-catalyzed preparation of the1,4-diene for the total synthesis of (-)-mycalamide A.

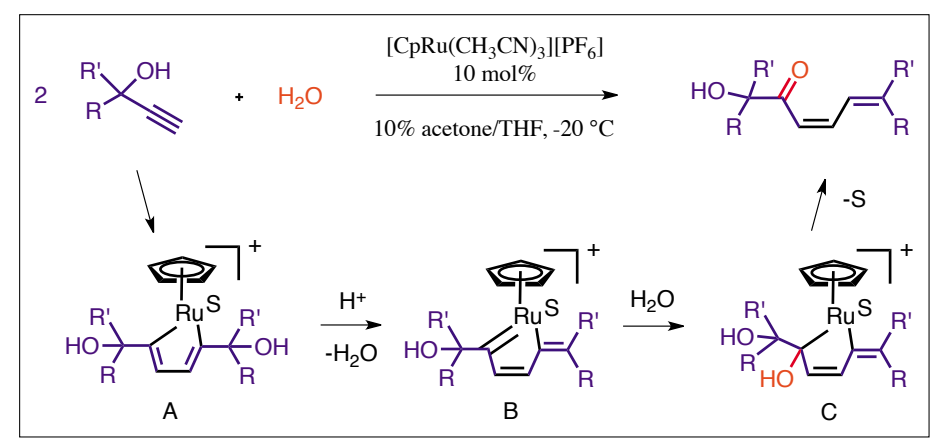

Scheme 7. [CpRu]catalyzed dimerization of propargylic alcohols.

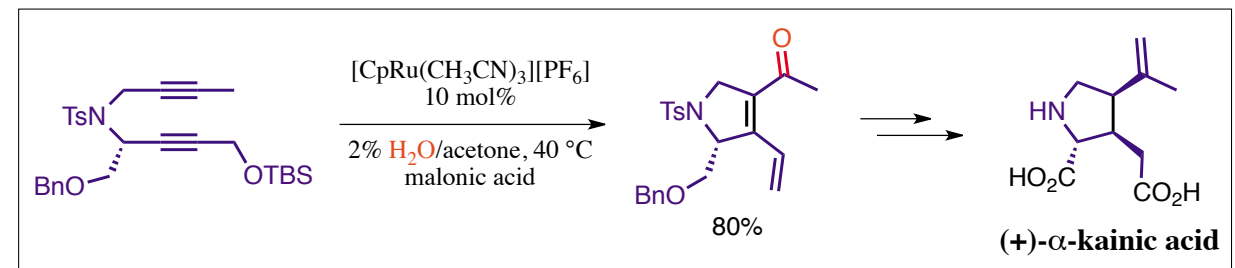

Scheme 8. [CpRu]-catalyzed cyclic precursor for the synthesis of $(+)-\alpha-$-kainic acid.

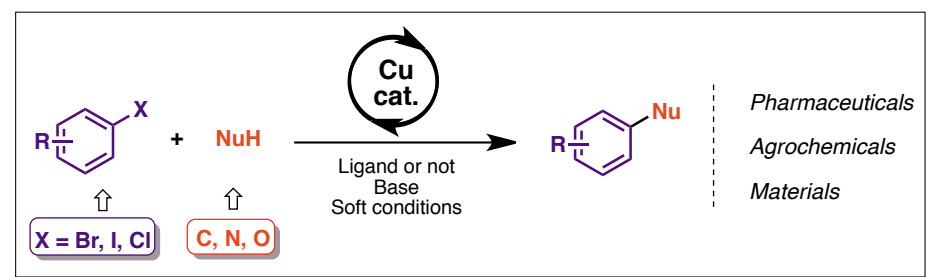

Scheme 9. Coppercatalyzed arylation of nucleophiles. 
formation is catalyzed by a combination of $10 \%$ of $\mathrm{Cu}(\mathrm{acac})_{2}$ and $30 \%$ of $\beta$-diketone (dibenzoylmethane) as ligand in DMF in the presence of $\mathrm{K}_{2} \mathrm{CO}_{3}$ as base (Scheme 10). ${ }^{[28]}$

\subsection{2 $\alpha$-Arylation of Ketones}

In 2012, we engaged our efforts on a real challenge in modern organic chemistry: the $\alpha$-arylation of ketones by catalysis with a copper system. This highly useful reaction had been rediscovered and generalized by Miura, Hartwig and Buchwald around 1997 and catalyzed by palladium/ complex diphosphine ligands. ${ }^{[29]}$ No other metal source, except nickel in the seminal works of Semmelhack, ${ }^{[30]}$ was able to catalyze and perform this transformation. Our discovery of an efficient catalytic system based on $10 \%$ of $\mathrm{CuI}$ and $10 \%$ of ligand (diketone or phenanthroline-type ligands) afforded a cheaper and simpler alternative for this transformation. After $24 \mathrm{~h}$ reaction time in $t$ - $\mathrm{BuOH}$ or in dioxane, the corresponding $\alpha$-arylated ketones were obtained in fair to excellent yields (Scheme 11). [31]

This pioneering copper methodology was directly applied to the synthesis of tamoxifen, one of the world's most commonly administered drugs for treatment of breast cancer. This route for tamoxifen constitutes one of the most direct routes to date (Scheme 12).

\subsection{C-N Bond Formation Catalyzed by Copper}

\subsubsection{Anilines and Polyarylamines}

For more than a century the copper-mediated coupling of aryl and vinyl halides to aromatic nitrogen heterocycles or amines, the Ullmann ${ }^{[32]}$ condensations, have been well known. However, Ullmann-type coupling has not been employed to its full potential for a long time. During a century the synthetic scope of these reactions was restricted because of the harsh reaction conditions, restricted range of suitable substrates, and the poor formation rates obtained. Finally in 2001, two research groups ${ }^{[33]}$ discovered versatile and very efficient new copper/ligand systems for the formation of $\mathrm{C}-\mathrm{C}, \mathrm{C}-\mathrm{N}$, and $\mathrm{C}-\mathrm{O}$ bonds that enabled the use of only catalytic amounts of metal under much milder conditions $\left(90-110^{\circ} \mathrm{C}\right)$. One of these groups is the team of Dr. M. Taillefer, that I initially joined in September 2006 (Scheme 9).

Thus it became evident that I had begun my assistant professor career in the very active field of revisited Ullmann-type reactions. In 2006, a simple copper catalytic system (based on $\mathrm{CuI}$ and acac ligand) for the direct amination of aryl halides with aqueous ammonia was discovered in the

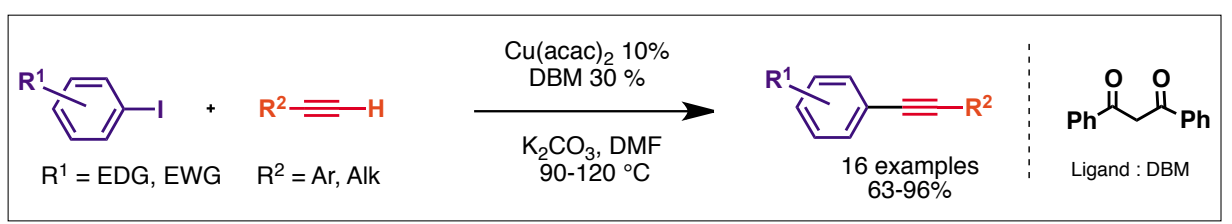

Scheme 10. Palladium-free Sonogashira-type reaction.

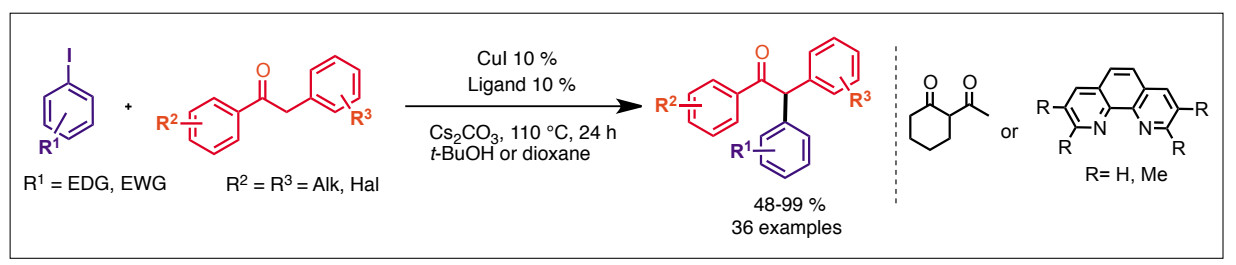

Scheme 11. Copper-catalyzed $\alpha$-arylation of ketones.

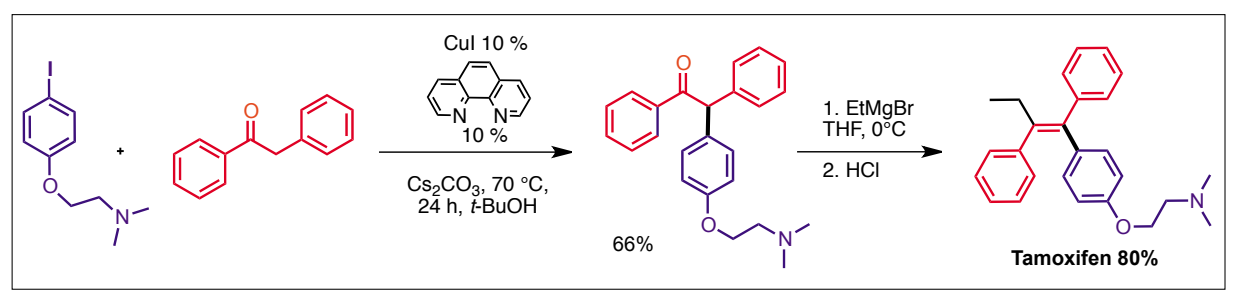

Scheme 12. Copper-catalyzed synthesis of tamoxifen via $\alpha$-arylation of deoxybenzoin. group. ${ }^{[34]}$ At that time this reaction constituted the first example of utilization of ammonia in an Ullmann-type reaction. Following this breakthrough achieved in the lab, we decided to extend the scope of this type of reaction and we focused our attention on the development of a simple route to polyarylamines. First attempts with $\mathrm{NH}_{3} \cdot \mathrm{H}_{2} \mathrm{O}$ failed in terms of selectivity, so we tried to use a simple surrogate of ammonia: lithium amide $\mathrm{LiNH}_{2}$. We rapidly demonstrated that a fine-tuning of conditions (stoichiometry of base and $\mathrm{LiNH}_{2}$ ) afforded symmetrical di- and triarylamines in a simple one-pot reaction (Scheme 13). [35]

At this point, we planned to further develop this one-pot method for the generation of unsymmetrical di- and triaryl- amines. We found the trick by adding a second source of aryl halides after $6 \mathrm{~h}$ of reaction in classical conditions catalyzed by a ligandless copper system (Scheme 14).

Finally, we showed the power of this simple methodology for the synthesis of triarylamines, especially $\mathrm{N}$-arylated dipyridylamines. Starting from diverse aryl iodide and 2 equiv. 2-bromopyridine, we were able to isolate these bidentate molecules that could be very useful as ligands in coordination chemistry (Scheme 15).

Furthermore the synthesis of an amine with three different aryl substituents was achieved in acceptable yields (Scheme 16). This very easy route to polyarylamines could constitute a simple and direct method for the synthesis of starburst molecular

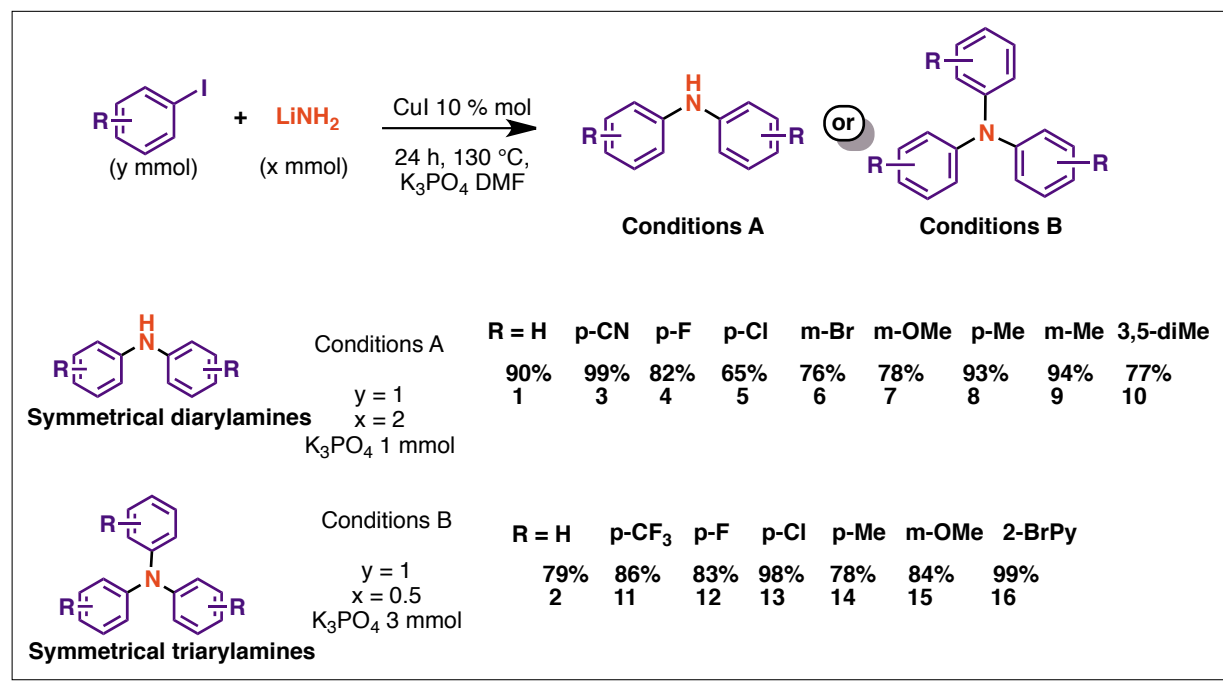

Scheme 13. Access to symmetrical di- and triarylamines. 


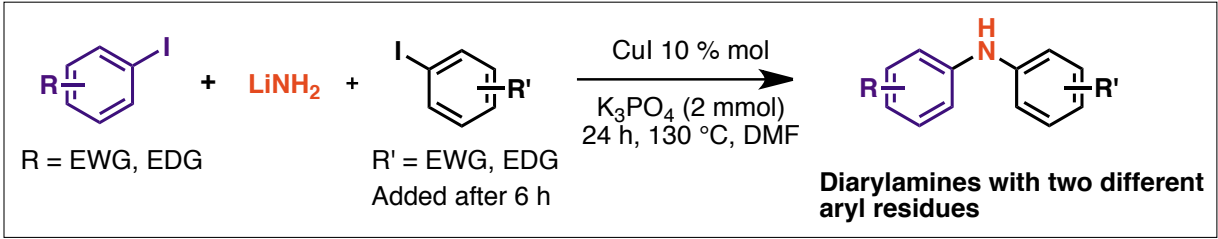

Scheme 14. Access to diarylamines with two different aryl residues.

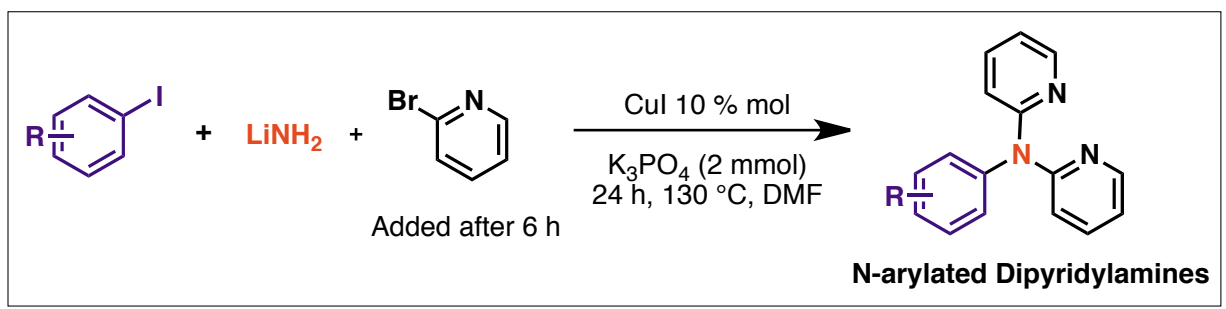

Scheme 15. One-pot access to $\mathrm{N}$-arylated dipyridylamines.

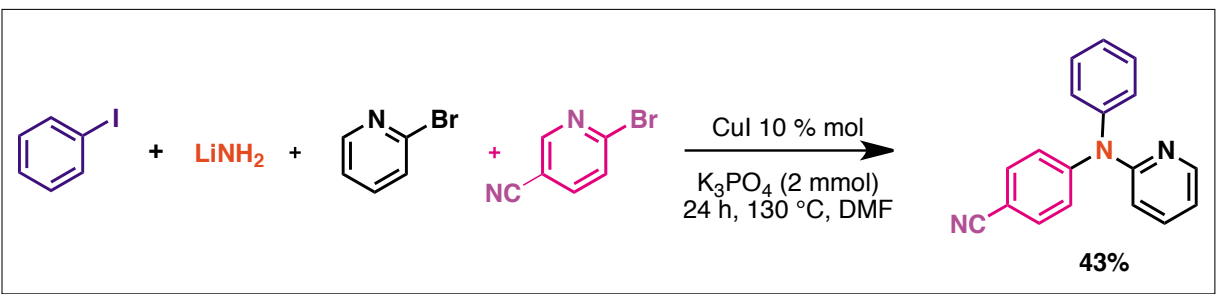

Scheme 16. Copper-catalyzed synthesis of triarylamines with three different aryl residues.

structures for photovoltaic devices ${ }^{[36]}$ and charge-transport materials. ${ }^{[37]}$

\subsubsection{N-substituted Amides}

The amide function is one of the most relevant key structural motifs in life science chemistry. Every novel method to modify or to substitute it is highly important for human and plant healthcare sciences. The classical catalytic and mediated reactions for $\mathrm{N}$-arylation or $\mathrm{N}$-alkylation of amides are the Buchwald-Hartwig reaction ${ }^{[38]}$ (from aryl halides catalyzed by a palladium/ligand system), the Goldberg reaction ${ }^{39]}$ (from aryl halides catalyzed by a copper/ligand system) and the Chan-Lam reaction ${ }^{[40]}$ (copper-mediated cross coupling reaction starting from boronic acid molecules).

In 2010, we started a scientific collaboration with Bayer Crop Science for the modification of secondary amides. First we became interested in the development of a catalytic system able to arylate selectively the $\mathrm{N}$-atom of secondary amides avoiding the use of expensive and complex palladium/phosphorous ligands. Following an extensive study of efficient conditions able to catalyze this reaction with a copper/ligand catalytic system, we were able to propose a general methodology for the $\mathrm{N}$-arylation of starting amides. This example constitutes the first one described for that transformation (Scheme 17). ${ }^{[41]} 5 \%$ of $\mathrm{CuI}$ and $10 \%$ of commercially available $\beta$-diketone ligand compose the optimal catalytic system.

In a second goal, we wished to functionalize aromatic and aliphatic secondary amides with a cyclopropyl group. Thanks to its metabolic stability the cyclopropyl moiety is a privileged backbone in agrochemical science. ${ }^{[42]}$ After literature analysis, we decided to study the N-cyclopropylation by a Chan-Lam type reaction under air conditions. ${ }^{[40]}$ Thus we demonstrated that using 1 equiv. $\mathrm{Cu}(\mathrm{OAc})_{2}, 3$ equiv. pyridine and 0.5 equiv. $\mathrm{Cs}_{2} \mathrm{CO}_{3}$, we were able to obtain a wide variety of $\mathrm{N}$-cyclopropylated tertiary amides. For that transformation cyclopropyl boronic acid was the most efficient coupling partner (Scheme 18). This method represents a very useful access for cyclic and acyclic amides functionalized by a cyclopropyl motif.[43]

\subsection{C-O Bond Formation Catalyzed by Copper}

In 1904 Fritz Ullmann reported his seminal work on the first example of cop- per-mediated $\mathrm{C}-\mathrm{O}$ bond formation from an aryl halide and a phenol derivative under harsh conditions. ${ }^{[44]}$ Analogously to the Ullmann-type $\mathrm{C}-\mathrm{N}$ cross coupling reaction, a breakthrough in this chemistry was established 100 years later in our group by the introduction of a ligand that allowed this transformation to be catalyzed by copper under smooth conditions. ${ }^{[33]}$ Since that renaissance many efforts have been successfully made to develop lots of $\mathrm{Cu}$-catalyzed systems able to couple aryl halides and different $\mathrm{O}$-nucleophiles.

\subsubsection{Direct Access to Phenol and its Derivatives}

In 2008 we decided to study the possibility to generate phenols from aryl halides catalyzed by copper. Surprisingly in the literature there were no examples of coppercatalyzed hydroxylation of aryl halides. It is noteworthy that some groups developed a version of this reaction catalyzed by palladium and complex phosphorous ligands. ${ }^{[45]}$ Nevertheless the high cost of this system limited industrial applications in larger scale.

Starting from phenyliodide in the presence of various copper sources and ligands, we tested several hydroxide salts in different solvents. Then we rapidly found that the crucial point for this transformation was the use of a mixture of solvents: DMSO/ water (1/1). Following this observation, we were able to propose an efficient catalytic system based on $10 \%$ of $\mathrm{CuI}$ and $50 \%$ of $\beta$-diketone (dibenzoylmethane) for the direct hydroxylation of aryl iodides. The most efficient $\mathrm{O}$-source was $\mathrm{CsOH}$, and the corresponding phenol derivatives were obtained in excellent yields (Scheme 19). ${ }^{[46]}$

Based on a methodology discovered in our group for the copper-catalyzed cyanation of aryl bromides, ${ }^{[47]}$ we performed the hydroxylation of the latter (cheaper and more abundant) via an in situ reaction of halogen exchange with $\mathrm{NaI}$ followed by the generation of corresponding phenols. The same catalytic system was used for both reactions. In this case, a diamine ligand (DMEDA) is necessary to obtain

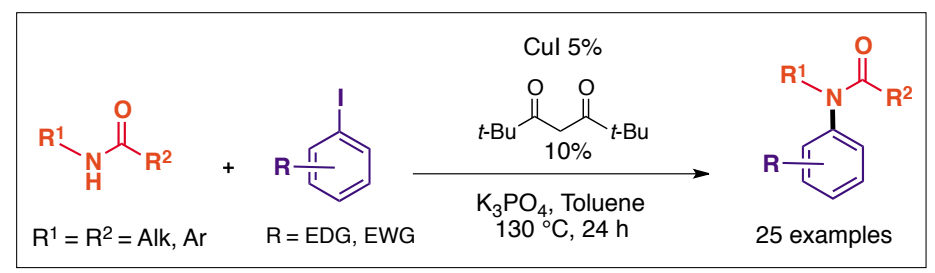

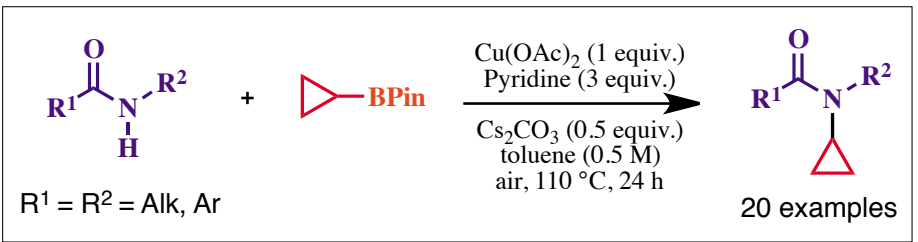

Scheme 17 $\mathrm{N}$-arylation of secondary amides.
Scheme 18. Coppermediated cyclopropylation of secondary amides. 
the corresponding products with the best yields (Scheme 20).

\subsubsection{Original Access to Diarylether}

In the past, our group has developed efficient catalytic systems for the formation of diarylethers based on a combination of copper salts and commercially available ligands. ${ }^{48]}$ This methodology could undergo the formation of valuable diarylethers ${ }^{[49]}$ (useful backbones for natural product synthesis and materials science) from aryl iodides, bromides or chlorides. In collaboration with the group of M. Wong Chi Man we also reported heterogeneous copper catalytic systems for this transformation based on the immobilization of ligands (bispyridinyl- or $\beta$-diamide-type ligands) on hybrid silica. ${ }^{[50]}$ It is noteworthy that heterogenized ligands permitted a very low amount of copper leaching $(<30 \mathrm{ppm})$ in the crude phases containing the desired diarylethers at the end of reaction (Scheme 21).

In 2010 following the discovery of the first copper-catalyzed hydroxylation of aryl halides, ${ }^{[46]}$ we focused our efforts on the development of a very practical synthesis of symmetrical and unsymmetrical diarylethers. This strategy was based on using only aryl halides as sources of aryl moieties and water or $\mathrm{MOH}$ as sources of O-nucleophiles. In fact, the key reaction was based on the hydroxylation published in 2009:[46] our goal was not to stop at the phenol cross-coupling product, but to carry on this reaction by generating in situ a phenolate able to react with a second source of aryl halide. By fine-tuning the solvent mixture and the nature of $\mathrm{O}$-nucleophile, we found that a catalytic system based on $10 \%$ of $\mathrm{CuI}$ and $30 \%$ of $\beta$-diketone is able to promote the double arylation of $\mathrm{H}_{2} \mathrm{O}$ in the presence of 3 equiv. base $\left(\mathrm{K}_{3} \mathrm{PO}_{4}\right)$ (Scheme 22). ${ }^{[51]}$

We then examined the range of this methodology by introducing a second source of aryl halides (iodides, bromides and chlorides) after six hours of reaction. The main goal was achieved: the one-pot direct synthesis of unsymmetrical diarylethers from two aryl halide sources. The conditions are different than for the access of symmetrical diarylether as the $\mathrm{O}$ nucleophile source is $\mathrm{CsOH}$, nevertheless this catalytic system afforded the corresponding products in good yields and excellent selectivity (Scheme 23).

\subsection{Industrial Applications}

Since its renaissance, the revisited Ullmann-type reactions have permitted the synthesis of many molecules of interest in human-, plant- and animal healthcare. Recently excellent reviews have covered the field of copper-catalyzed cross coupling reactions for the synthesis of natural prod-

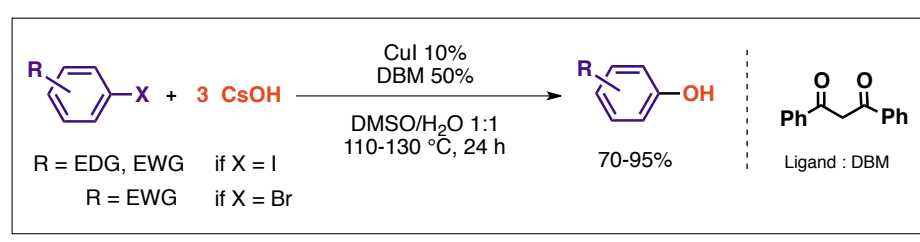

Scheme 19. Coppercatalyzed hydroxylation of aryl halides.

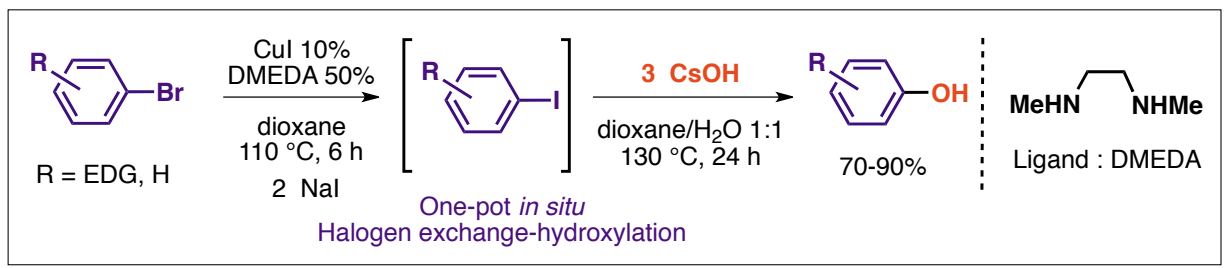

Scheme 20. Synthesis of phenols derivatives from aryl bromides.

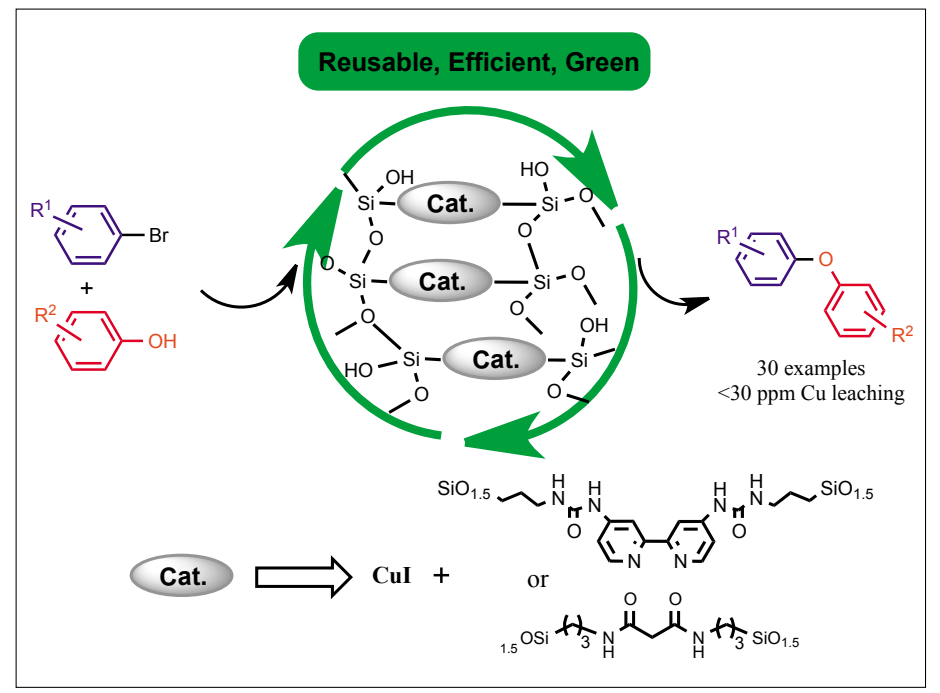

Scheme 21

Recyclable coppercatalytic systems for O-arylation of aryl bromides.

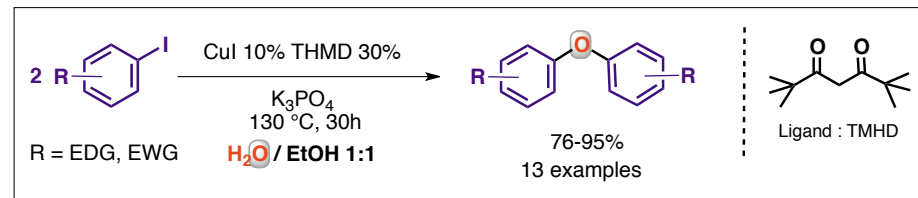

Scheme 22.

Synthesis of symmetrical diarylethers from aryl iodides.

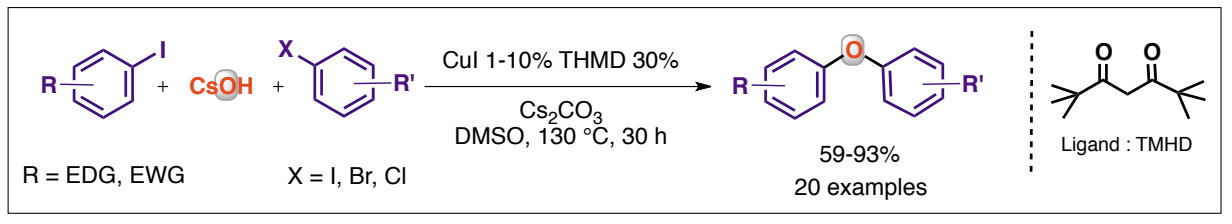

Scheme 23. Synthesis of unsymmetrical diarylethers from two sources of aryl halides.

ucts. ${ }^{52]}$ As an example among many others, the group of Fukuyama described the total synthesis of yatakemycin, a potent natural antitumoral and antibiotic, achieved by five intramolecular $\mathrm{C}-\mathrm{N}$ cross-coupling reactions catalyzed or mediated by copper. ${ }^{[53]}$ For the synthesis of abyssenine A, a natural cyclopeptide alkaloid presenting many biological activities, Evano et al. used a strategy based on $\mathrm{C}-\mathrm{O}$ and $\mathrm{C}-\mathrm{N}$ Ullmann cross-coupling reactions catalyzed by two different catalytic systems with $\mathrm{CuI}$ and respectively phenanthroline and diamine type ligands (Scheme 24). ${ }^{54]}$

Besides many impressive examples in the total synthesis of natural products using the copper-catalyzed cross coupling reactions for the formation of $\mathrm{C}-\mathrm{C}, \mathrm{C}-\mathrm{N}$ and $\mathrm{C}-\mathrm{O}$ bonds, many chemical companies rapidly adopted these methodologies for the large-scale production of molecules marketed for pharmaceutical, agrochemical and material purposes.

As demonstrated in Fig. 2, the scope of applications for these methodologies is very broad in terms of bonds formed and the nature of pharmaceutical target. It is noteworthy that the employed copper catalytic systems to form the underlined bonds in Fig. 2 are used for the production of the bioactive targets in multikilogram scale.

Many polymer and material sciences 


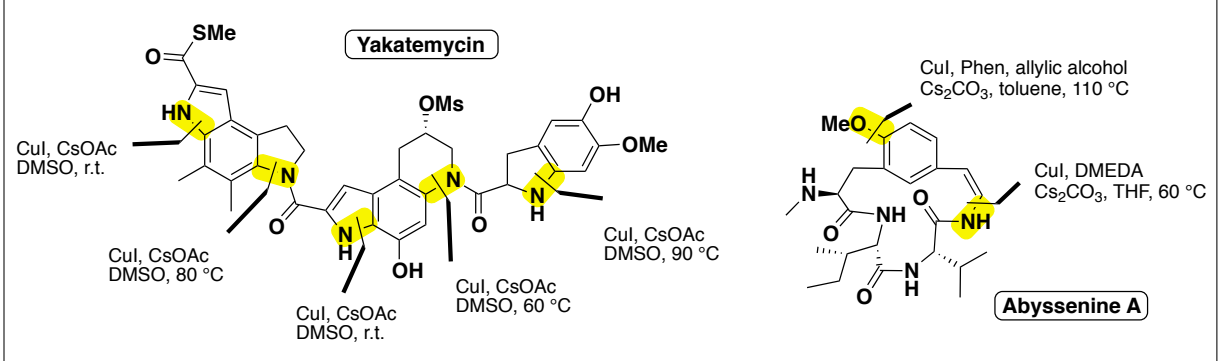

Scheme 24. Natural products synthesis assisted by copper-catalyzed arylation of nucleophiles.

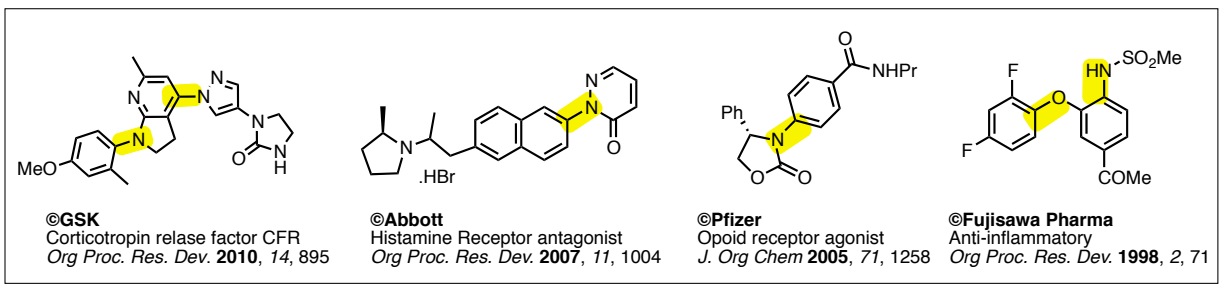

Fig. 2. Examples of industrial production of drugs assisted by copper-catalyzed arylation of nucleophiles.

\section{Conclusions}

companies have also been interested in incorporating copper-catalyzed crosscoupling reactions in their processes due to the low cost and abundant availability of copper sources. Representative examples of application are presented in Fig. 3 for large-scale production (multi-kilogram to tons of products). Target molecules represented a wide spectrum of what molecular chemistry could propose in the field of polymers, colorants, as well as electroluminescent dyes for photovoltaic applications (Fig. 3).

Recent decades have witnessed impressive progress in homogeneous catalysis by late transition-metal systems. Among them, 'à la carte' homogeneous ruthenium- and copper-based catalytic systems have gained a place of choice for synthesis of molecules of interest due to their versatility and efficiency. Despite the recent progress in the field of cross-coupling copper-catalyzed reactions, our strategies are usually limited to the activation of aryl iodides and bromides. A future major goal will be to develop efficient catalytic systems for the cross-coupling of less reactive aryl chlorides and aryl sulfonates. Notable

efforts have also to be engaged to decrease the amount of copper and ligand needed for these useful synthetic transformations. For that, elucidating the mechanism of Ullmann-type reactions could allow the chemical community to achieve the major goals listed above. With regard to the synthesis of complex molecules of interest, the power of ruthenium and copper catalysts opens up a large scope of useful possibilities for the academic and industrial communities.

Received: August 18, 2015

[1] a) B. M. Trost, F. D. Toste, A. B. Pinkerton, Chem. Rev. 2001, 101, 2067; b) B. M. Trost, M. U. Frederiksen, M. T. Rudd, Angew. Chem. Int. Ed. 2005, 44, 6630.

[2] a) R. H. Grubbs, Angew. Chem. Int. Ed. 2006 45, 3760; b) A. H. Hoveyda, J. Org. Chem. 2014, 79, 4763 .

[3] a) M. F. Semmelhack, A. Chlenov, 'Topics in Organometallic Chemistry', 2004, pp 44; b) F. C. Pigge, J. J. Coniglio, Curr. Org. Chem. 2001, 5,757 ; c) A. J. Pearson, J.-N. Heo, Tetrahedron Lett. 2000, 41, 5991; d) C. W. West, D. H. Rich, Org. Lett. 1999, 1, 1819 .

[4] a) G. Jaouen, A. Vessieres, I. S. Buttler, Acc. Chem. Res. 1993, 26, 361; b) W. H. Soine, C. E. Guyer, F. F. Knapp, J. Med. Chem. 1984, 27, 803.

[5] V. Alezra, G. Bernardinelli, C. Corminboeuf, U. Frey, E. P. Kündig, A. E. Merbach, C. M. Saudan, F. Viton, J. Weber, J. Am. Chem. Soc. 2004, 126, 4843 .
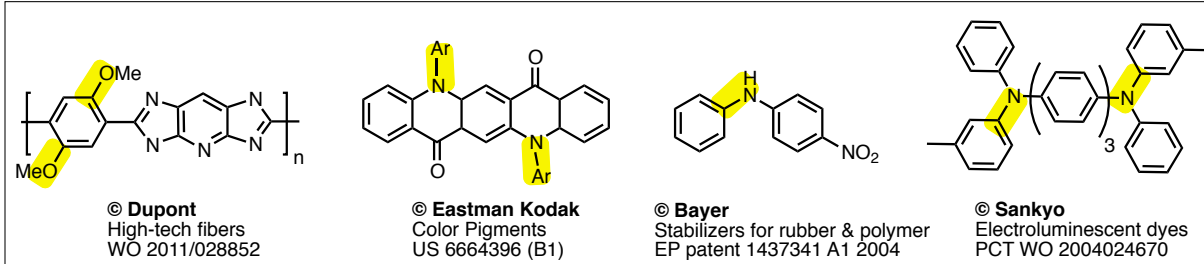

Fig. 3. Industrial production of commodity chemicals using Ullmann-type copper-catalyzed reactions.
[6] K. Miyata, H. Kutsuna, S. Kawakami, M. Kitamura, Angew. Chem. Int. Ed. 2011, 50, 4649

[7] T. P. Gill, K. R. Mann, Organometallics 1982, 1,485 .

[8] B. M. Trost, C. M. Older, Organometallics 2002, 21, 2544.

[9] E. P. Kündig, F. R. Monnier, Adv. Synth. Cat. 2004, 346, 901.

[10] a) C. Tortoreto, T. Achard, W. Zeghida, M. Austeri, L. Guénée, J. Lacour, Angew. Chem. Int. Ed. 2012, 51, 5847; b) M. Austeri, D. Rix, W. Zeghida, J. Lacour, Org. Lett. 2011, 13, 1394; c) M. Austeri, D. Linder, J. Lacour, $A d v$. Synth. Catal. 2010, 352, 3339; d) T. Achard, C. Tortoreto, A. I. Poblador-Bahamonde, L. Guénée, T. Bürgi, J. Lacour, Angew. Chem. Int. Ed. 2014, 53, 6140 .

[11] a) A. Zampella, M. V. D'Auria, L. Minale, C. Debitus, C. J. Roussakis, J. Am. Chem. Soc. 1996, 118, 11085; b) A. Zampella, M. V. D'Auria, L. Minale, Tetrahedron 1997, 53, 3243.

[12] a) B. M. Trost, J. L. Gunzner, J. Am. Chem. Soc. 2001, 123, 9449; b) B. M. Trost, J. L. Gunzner, O. Dirat, Y. H. Rhee, J. Am. Chem. Soc. 2002, 124, 10396.

[13] N. B. Perry, J. W. Blunt, M. H. G. Munro, J. Am. Chem. Soc. 1988, 110, 4850 .

[14] B. M. Trost, H. Yang, G. D. Probst, J. Am. Chem. Soc. 2004, 126, 48.

[15] B. M. Trost, M. T. Rudd, J. Am. Chem. Soc. 2001, 123,8862

[16] Several methodologies for cycloisomerisation reactions have been developed with this catalyst. For cycloisomerisation of enynes, see: B. M. Trost, E. M. Ferreira, A. C. Gutierrez, J. Am. Chem. Soc. 2008, 130, 16176.

[17] B. M. Trost, M. T. Rudd, Org. Lett. 2003, 5, 1467.

[18] B. M. Trost, C. E. Stivala, K. L. Hull, A. Huang, D. R. Fandrick, J. Am. Chem. Soc. 2014, 136, 88.

[19] B. M. Trost, J. Waser, A. Meyer, J. Am. Chem. Soc. 2007, 129, 14556

[20] B. M. Trost, H. Yang, O. R. Thiel, A. J. Frontier, C. S. Brindle, J. Am. Chem. Soc. 2007, 129, 2206.

[21] B. M. Trost, J. P. N. Papillon, T. Nussbaumer, $J$. Am. Chem. Soc. 2005, 127, 17921.

[22] B. M. Trost, L. Dong, G. M. Schroeder, J. Am. Chem. Soc. 2005, 127, 10259

[23] B. M. Trost, M. T. Rudd, Org. Lett. 2003, 5, 4599.

[24] C. Cook, X. Guinchard, F. Liron, E. Roulland, Org. Lett. 2010, 12, 744 .

[25] a) M. Taillefer, H.-J. Cristau, P. P. Cellier, J.-F Spindler, Env. SAU2001-1009 and SAU200101044; patents Fr2833947-WO0353225 (Pr. Nb. Fr 2001 16547); b) M. Taillefer, H.-J. Cristau, P. P. Cellier, J.-F. Spindler, A. Ouali, Fr2840303WO03101966 (Pr. Nb. Fr200206717);

[26] a) H. Doucet, J.-C. Hierso, Angew. Chem. Int $E d .2007,46,834$; b) R. Chinchilla, C. Najera, Chem. Rev. 2007, 107, 874; c) E.-I.Negishi, L. Anastasia, Chem. Rev. 2003, 103, 1979.

[27] For a review on acetylenic coupling, see: P. Siemsen, R. C. Livingston, F. Diederich, Angew. Chem. Int. Ed. 2000, 39, 2632.

[28] F. Monnier, F. Turtaut, L. Duroure, M. Taillefer, Org. Lett. 2008, 10, 3203.

[29] a) T. Satoh, Y. Kawamura, M. Miura, M. Nomura, Angew. Chem. Int. Ed. Engl. 1997, 36, 1740; b) B. C. Hamann, J. F. Hartwig, J. Am. Chem. Soc. 1997, 119, 12382; c) M. Palucki, S. L. Buchwald, J. Am. Chem. Soc. 1997, 119, 11108; d) S. T. Sivanandan, A. Shaji, I. Ibnusaud, C. C. C. Johansson Seechurn, T. J. Colacot, Eur. J. Org. Chem. 2015, 38.

[30] M. F. Semmelhack, B. P. Chong, R. D. Stauffer, T. D. Rogerson, A. Chong, L. D. Jones, J. Am. Chem. Soc. 1975, 97, 2507. 
[31] a) G. Danoun, A. Tlili, F. Monnier, M. Taillefer, Angew. Chem. Int. Ed. 2012, 51, 12815; b) M. Taillefer, F. Monnier, A. Tlili, G. Danoun, PCT Int. Appl. 2013, WO 2013 EP61697 20130606

[32] a) F. Ullmann, Ber. Dtsch. Chem. Ges. 1903 36, 2382; b) F. Ullmann, E. Illgen, Ber. Dtsch. Chem. Ges. 1914, 47, 380.

[33] a) M. Taillefer, H.-J. Cristau, P. P. Cellier, J.-F Spindler, Env. SAU2001-1009 and SAU200101044; patents Fr2833947-WO0353225 (Pr. Nb. Fr 2001 16547); M. Taillefer, H.-J. Cristau, P. P. Cellier, J.-F. Spindler, A. Ouali, Fr2840303WO03101966 (Pr. Nb. Fr200206717); b) S. L. Buchwald, A. Klapars, J. C. Antilla, G. E. Job, M. Wolter, F. Y. Kwong, G. Nordmann, E. J. Hennessy, WO02/085838 (priority number US 0286268, 2001).

[34] a) M. Taillefer, N. Xia, PCT Int. Appl. 2009, WO 2009050366 A2 20090423; b) N. Xia, M Taillefer, Angew. Chem. Int. Ed. 2009, 48, 337.

[35] A. Tlili, F. Monnier, M. Taillefer, Chem. Commun. 2012, 48, 5408 .

[36] Z. Ning, H. Tian, Chem. Commun. 2009, 5483.

[37] R. A. Klenkler, G. Voloshin, J. Phys. Chem. C 2011, 115, 16777

[38] a) D. S. Surry, S. L. Buchwald, Angew. Chem. Int. Ed. 2008, 47, 6338; b) J. F. Hartwig, Nature 2008, 455,314

[39] a) I. Goldberg, Ber. Dtsch. Chem. Ges. 1906, 39, 1691; b) I. Goldberg, Ber. Dtsch. Chem. Ges. 1907, 40, 4541; c) F. Monnier, M. Taillefer, Angew. Chem. Int. Ed. 2009, 48, 6954; d) G. Evano, N. Blanchard, M. Toumi, Chem. Rev. 2008, 108, 3054
[40] a) J. X. Qiao, P. Y. S. Lam, Synthesis 2011, 829; b) K. S. Rao, T.-S. Wu, Tetrahedron 2012, 68, 7735; c) D. M. T. Chan, K. L. Monaco, R. P. Wang, M. P. Winters, Tetrahedron Lett. 1998, 39, 2933; d) P. Y. S. Lam, C. G. Clark, S. Saubern, J. Adams, M. P. Winters, D. M. T. Chan, A. Combs, Tetrahedron Lett. 1998, 39, 2941.

[41] E. Racine, F. Monnier, J.-P. Vors, M. Taillefer, Org. Lett. 2011, 13, 2818.

[42] C. L. Shaffer, S. Harriman, Y. M. Koen, R. P. Hanzlik, J. Am. Chem. Soc. 2002, 124, 8268.

[43] E. Racine, F. Monnier, J.-P. Vors, M. Taillefer, Chem. Commun. 2013, 49, 7412.

[44] a) F. Ullmann, Ber. Dtsch. Chem. Ges. 1904, 37, 853; b) F. Ullmann, P. Sponagel, Ber. Dtsch. Chem. Ges. 1905, 38, 2211

[45] a) K.W. Anderson, T. Ikawa, R. E. Tundel, S. L. Buchwald, J. Am. Chem. Soc. 2006, 128, 10694; b) G. Chen, A. S. C. Chan, F. Y. Kwong, Tetrahedron Lett. 2007, 48, 473; c) B. J. Gallon, R.W. Kojima, R. B. Kaner, P. L. Diaconescu, Angew. Chem. Int. Ed. 2007, 46, 7251; d) T. Schulz, C. Torborg, B. Schaffner, J. Huang, A. Zapf, R. Kadyrov, A. Borner, M. Beller, Angew. Chem. Int. Ed. 2009, 48, 918;

[46] a) Our results were published as a patent in 2009: Procédé de Synthèse de Phénols, M. Taillefer, F. Monnier, A. Tlili, N. Xia, FR 02767, 2009; b) A. Tlili, N. Xia, F. Monnier, M. Taillefer, Angew. Chem. Int. Ed. 2009, 48, 8725.
[47] H.-J. Cristau, A. Ouali, J.-F. Spindler, M. Taillefer, Chem. Eur. J. 2005, 11, 2483.

[48] a) H.-J. Cristau, P. P. Cellier, S. Hamada, J.-F. Spindler, M. Taillefer, Org. Lett. 2004, 6, 913; b) A. Ouali, J.-F. Spindler, H.-J. Cristau, M. Taillefer, Adv. Synth. Catal. 2006, 348, 499; c) N. Xia, M. Taillefer, Chem. Eur. J. 2008, 14, 6037.

[49] a) J. Zhu, Synlett 1997, 133; b) F. Theil, Angew. Chem. Int. Ed. 1999, 38, 2345; c) X. Li, T. G. Upton, C. L. D. Gibb, B. C. Gibb, J. Am. Chem. Soc. 2003, 125, 650; c) R. Frlan, D. Kikelj, Synthesis 2006, 2271; d) E. N. Pitsinos, V. P. Vidali, E. A. Couladouros, Eur. J. Org. Chem. 2011, 1207.

[50] a) S. Benyahya, F. Monnier, M. Taillefer, M. Wong Chi Man, C. Bied, F. Ouazzani, $A d v$. Synth. Cat. 2008, 350, 2205; b) S. Benyahya, F. Monnier, M. Wong Chi Man, C. Bied, F. Ouazzani, M. Taillefer, Green Chem. 2009, 11, 1121.

[51] a) Our results were published as a patent in 2010: FR Patent (2010), FR20100057099 20100907; b) A. Tlili, F. Monnier, M. Taillefer, Chem. Eur. J. 2010, 16, 12299.

[52] a) G. Evano, N. Blanchard, M. Toumi, Chem. Rev. 2008, 108, 3054; b) K. Okano, H. Tokuyama, T. Fukuyama, Chem. Commun. 2014, 50, 13650

[53] K. Okano, H. Tokuyama, T. Fukuyama, J. Am. Chem. Soc. 2006, 128, 7136.

[54] M. Toumi, F. Couty, G. Evano, J. Org. Chem. 2007, 72, 9003 